Check for updates

Cite this: RSC Adv., 2019, 9, 11289

Received 22nd January 2019

Accepted 19th March 2019

DOI: $10.1039 / c 9 r a 00573 k$

rsc.li/rsc-advances

\section{The design and fabrication of a multilayered graded GNP/Ni/PMMA nanocomposite for enhanced EMI shielding behavior $\dagger$}

\author{
Hye Ji Im, ${ }^{a}$ Jae Young Oh, ${ }^{\mathrm{c}}$ Seongwoo Ryu ${ }^{\mathrm{b}}$ and Soon Hyung Hong (DD *a
}

A multilayered graded structure can maximize the electromagnetic interference (EMI) shielding properties of a nanocomposite for a specific amount of a conductive filler in a polymer matrix. In this study, multilayered graded nanocomposites of graphene nanoplatelet (GNP)/Ni/polymethyl methacrylate (PMMA) were developed to achieve enhanced EMI shielding behavior. Both multilayered and monolayered nanocomposites were fabricated by controlling the compositions of GNP/Ni in the PMMA matrix. The contributions of the multilayered nanocomposite to EMI shielding were investigated and compared with the shielding effectiveness of the monolayered nanocomposite. The multilayered nanocomposite shows enhanced shielding effectiveness of around $61 \mathrm{~dB}$ in the X-band, which is more than three orders of magnitude higher than that of the monolayered nanocomposite. It has been confirmed that the measurements of reflection, absorption and total shielding effectiveness are in good accordance with the theoretically calculated results. The primary shielding mechanism was absorption due to conductive dissipation. The enhanced absorption of electromagnetic waves is attributed to an abrupt increase in the conductivity between layers in the direction of wave propagation in a multilayered nanocomposite due to impedance matching with the air and internal reflection between layers.

\section{Introduction}

Electromagnetic interference (EMI), especially in the highfrequency range of 8-12 GHz (the X-band), has led to problems in various fields where electromagnetic devices and military systems are used. ${ }^{\mathbf{1 - 3}}$ The degradation in the performances of control and communication systems and the leakage of information from military systems has increased the demand for EMI shielding materials. ${ }^{4-6}$

Metals, which have been used as conventional EMI shielding materials, have recently been found to suffer from reflection from their surfaces, corrosion susceptibility and high density. ${ }^{6-9}$ As a promising candidate for an EMI shielding material, graphene has gained attention due to its high electrical conductivity, low density and anti-corrosion resistance. ${ }^{\mathbf{1 0 - 1 2}}$ Since graphene produced via mechanical exfoliation or chemical vapor deposition has limitations in productivity, ${ }^{\mathbf{1 3 , 1 4}}$ the use of graphene nanoplatelet (GNP) is more suitable for industrial

${ }^{a}$ Department of Materials Science and Engineering, Korea Advanced Institute of Science and Technology (KAIST), 291 Daehak-ro, Yuseong-gu, Daejeon, 34141, Republic of Korea. E-mail: shhong@kaist.ac.kr; Tel: +82423503327

${ }^{b}$ Department of Advanced Materials Engineering, The University of Suwon, 17, Wauangil, Bongdam-eup, Hwaseong-si, Gyeonggi-do, Republic of Korea

'SK Hynix Inc, 2091, Gyeongchung-daero, Bubal-eub, Icheon-si, Gyeonggi-do, Republic of Korea

$\dagger$ Electronic supplementary information (ESI) available. See DOI: $10.1039 / \mathrm{c} 9 \mathrm{ra} 00573 \mathrm{k}$ applications. ${ }^{15}$ GNP, composed of hundreds of graphite layers stacked together and with an average thickness between 30 and $100 \mathrm{~nm}$, can offer more advantages such as higher intrinsic conductivity, much lower production cost and larger-scale production. $^{\mathbf{1 6 , 1 7}}$

In our previous study, nano-sized Ni particle-decorated GNP has been fabricated via a molecular-level mixing process, and its shielding capability has been investigated. ${ }^{15}$ The EMI shielding effectiveness (SE) of the GNP/Ni powders mixed in wax (30 wt\%) is around $40 \mathrm{~dB}$, whereas GNP itself (30 wt\%) shows the SE of around $26 \mathrm{~dB}$ in the $\mathrm{X}$-band. As a result of electrostatic interaction between $\mathrm{Ni}^{2+}$ ions and the functional groups on GNP, Ni nanoparticles are homogeneously anchored on GNP, and chemical bonds are formed between them. ${ }^{18}$ Chemical bonds play important roles in the enhancement of the absorption capability, providing magnetic dipoles that interact with magnetic wave and facilitating charge transfer between GNP and Ni nanoparticles. In addition, homogeneous distribution of nanoparticles promotes efficient formation of conductive networks while preventing agglomeration of GNP in a matrix; this leads to an increase in the electrical conductivity and EMI SE.

The application of the GNP/Ni nanocomposite as an EMI shielding material can be realized by adding GNP/Ni as a filler in a polymer matrix. The polymer matrix is lightweight and provides corrosion resistance and excellent processability to GNP/Ni. ${ }^{1,8}$ The GNP/Ni nanocomposite in the polymer matrix is 
expected to exhibit improved shielding capability by forming conductive networks of the GNP/Ni filler due to its high aspect ratio and electrical conductivity. ${ }^{\mathbf{1 9 2 0}}$ This is because the EMI shielding properties of the polymer nanocomposite incorporating the conductive filler are dependent on the aspect ratio, intrinsic conductivity and the amount of filler. ${ }^{21,22}$

Increasing the amount of the GNP/Ni filler is an indispensable choice to improve the EMI shielding performance. ${ }^{\mathbf{1 0}}$ However, this leads to agglomeration, which deteriorates the electrical conductivity and reflection of incident wave from the surface; this induces interference of the reflected wave. Thus, it is highly desirable that the incident wave must enter and be attenuated through a material to prevent additional interference. $^{23}$ Therefore, materials designed with multilayered structures with an increasing amount of conductive fillers can solve the previous challenges while preserving an average amount of fillers. $^{24}$

Herein, we report a multilayered structure of $\mathrm{GNP} / \mathrm{Ni} /$ polymethyl methacrylate (PMMA) nanocomposite with enhanced EMI shielding capability; moreover, this study involves the maximization of the EMI shielding properties of the GNP/Ni nanocomposite present in a specific amount in a matrix. To investigate the contribution of the multilayered structure to EMI shielding, multilayered nanocomposites with abrupt variation in the GNP/Ni concentration between layers and monolayered nanocomposites were designed and fabricated. The SE values of the two structures with the same total amount of GNP/Ni and sample thickness were compared with each other. Furthermore, the mechanism of EMI shielding of the multilayered nanocomposite was analyzed based on theoretical calculations.

\section{Materials and methods}

\subsection{Materials}

Graphene nanoplatelets (GNP) and polymethyl methacrylate (PMMA) were acquired from LG Chem. Ethylene glycol (99\%) and hydrazine monohydrate $(98 \%)$ were purchased from Junsei Chemical. Nickel(II) acetate $\left(\mathrm{Ni}\left(\mathrm{CH}_{3} \mathrm{CO}_{2}\right)_{2} \cdot\left(\mathrm{H}_{2} \mathrm{O}\right)_{4}\right)$ and polyvinyl pyrrolidone (PVP, $M_{\mathrm{w}}=55000 \mathrm{~g} \mathrm{~mol}^{-1}$ ) were purchased from Sigma-Aldrich.

\subsection{Fabrication of GNP/Ni by the molecular-level mixing process}

GNP (500 $\mathrm{mg}$ ) was dispersed in ethylene glycol $(500 \mathrm{~mL})$ by sonication for $2 \mathrm{~h}$. $\mathrm{Ni}\left(\mathrm{CH}_{3} \mathrm{CO}_{2}\right)_{2} \cdot\left(\mathrm{H}_{2} \mathrm{O}\right)_{4}(0.966 \mathrm{~g})$ was added and mixed with the GNP solution (at the volume ratio of $\mathrm{GNP} / \mathrm{Ni}$ about $9: 1)$. Then, aqueous $2 \mathrm{M} \mathrm{NaOH}(5 \mathrm{~mL})$ was added to the GNP/Ni ion solution, and the mixed solution was heated to $60{ }^{\circ} \mathrm{C}$. This process involves a chemical reaction that results in the oxidation of $\mathrm{Ni}$ ions to $\mathrm{NiO}$ and the formation of oxidized nano-sized powders. Subsequently, hydrazine monohydrate (5 $\mathrm{mL}$ ) was introduced with continuous heating at $60{ }^{\circ} \mathrm{C}$. The oxidized nanocomposite was reduced via the introduction of hydrazine monohydrate. After cooling the mixture, it was then filtered and rinsed with ethanol. The powders were dried at
$80{ }^{\circ} \mathrm{C}$ under vacuum and reduced into the GNP/Ni nanocomposite powders at $400{ }^{\circ} \mathrm{C}$ in $3 \mathrm{~h}$ under a hydrogen atmosphere.

\subsection{Fabrication of the GNP/Ni/PMMA nanocomposite}

Each layer of the GNP/Ni/PMMA nanocomposite (20 wt\%, $30 \mathrm{wt} \%$ and $40 \mathrm{wt} \%$ of $\mathrm{GNP} / \mathrm{Ni}$ in PMMA, separately) was prepared by solution blending. For each layer, the GNP/Ni powders were separately dispersed with PVP and PMMA in chloroform under stirring. The two mixtures were blended for 1-3 h at $65{ }^{\circ} \mathrm{C}$ under stirring until the solvent was evaporated, and then, they were dried under vacuum at $60{ }^{\circ} \mathrm{C}$ to completely remove the solvent. This process leads to homogeneous dispersion of GNP/Ni inside the PMMA layer. For abrupt concentration changes between layers, each layer was packed in a mold and pressed isostatically at room temperature under a pressure of $27 \mathrm{MPa}$ for $10 \mathrm{~min}$. Then, the GNP/Ni/PMMA samples were cut in a rectangular shape with the thickness of $2.5 \mathrm{~mm}$ (Fig. S1†).

\subsection{Characterization}

The microstructures of the samples were investigated by a scanning electron microscope (SEM, Hitachi S-4800). The electrical conductivities were measured using a four-point probe (AIT CMT-SR1000N). For the EMI SE measurement of the GNP/Ni/PMMA nanocomposite, a two-port vector network analyzer (Agilent 8722ES) was used to measure scattering parameters $\left(S_{12}\right.$ and $\left.S_{11}\right)$ by the waveguide method between 8 and $12 \mathrm{GHz}$. The samples were placed between two sections of the waveguide.

Transmission coefficient $(T)$, reflection coefficient $(R)$ and absorption coefficient (A) can be calculated from $S_{12}$ and $S_{11}$ by the following equations:

$$
\begin{gathered}
T=\left|S_{12}\right|^{2}=\left|E_{\mathrm{t}} / E_{\mathrm{i}}\right|^{2} \\
R=\left|S_{11}\right|^{2}=\left|E_{\mathrm{r}} / E_{\mathrm{i}}\right|^{2} \\
A+R+T=1
\end{gathered}
$$

where $E_{\mathrm{i}}, E_{\mathrm{t}}$ and $E_{\mathrm{r}}$ are the incident, transmitted and reflected electromagnetic energy, respectively. ${ }^{9}$

\section{Results and discussion}

\subsection{Monolayered and multilayered GNP/Ni/PMMA nanocomposites for EMI shielding}

Fig. 1 shows the schematic of the monolayered and multilayered GNP/Ni/PMMA nanocomposites. The monolayered and multilayered nanocomposites were designed based on the same average amount of GNP/Ni (30 wt\%) and sample thickness (2.5 $\mathrm{mm})$. The monolayered GNP/Ni/PMMA nanocomposite $\{30 \mathrm{wt} \%$ GNP/Ni in PMMA shown in Fig. 1(a) was fabricated by a general solution blending process, and its cross-section SEM images are shown in Fig. S2. $\dagger$ The GNP/Ni powders were observed to be homogeneously dispersed in the PMMA matrix. Fig. 1(b) depicts the image of the multilayered GNP/Ni/PMMA nanocomposite 

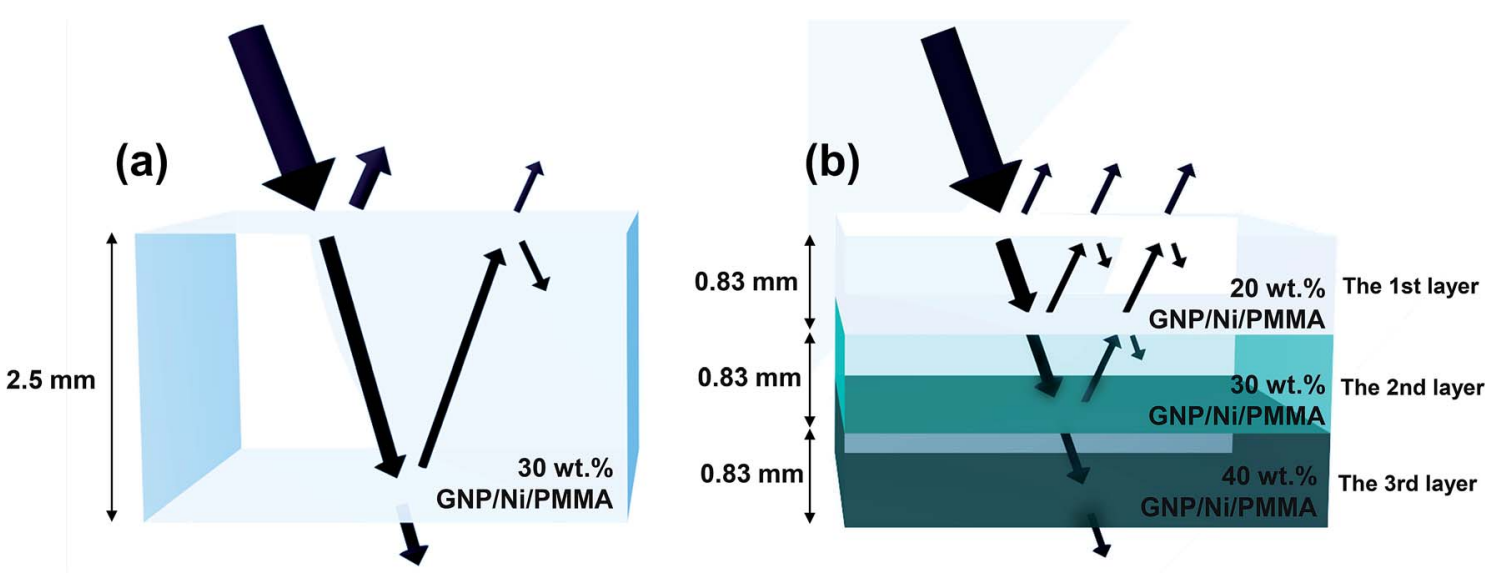

Fig. 1 Schematic of the (a) monolayered GNP/Ni/PMMA nanocomposite $\{30$ wt\% GNP/Ni $\}$ and (b) multilayered GNP/Ni/PMMA nanocomposite ( $\{20 \mathrm{wt} \% \mathrm{GNP} / \mathrm{Ni}\} /\{30 \mathrm{wt} \% \mathrm{GNP} / \mathrm{Ni}\} /\{40 \mathrm{wt} \% \mathrm{GNP} / \mathrm{Ni}\}$ ) (impedance of the $n$th layer $\left.\left(Z_{n}\right): Z_{1}>Z_{2}>Z_{3}\right)$. Monolayered and multilayered nanocomposites have the same average amount of GNP/Ni (30 wt\%) and total specimen thickness (2.5 mm).

( $\{20$ wt $\%$ GNP/Ni in PMMA $\} /\{30 w t \%$ GNP/Ni in PMMA $\} /\{40 w t \%$ GNP/Ni in PMMA\}). The average amount of GNP/Ni in PMMA was kept constant at $30 \mathrm{wt} \%$, and the amount of GNP/Ni for each layer inside the shielding material was changed; the concentration difference of GNP/Ni between layers was maintained at $10 \mathrm{wt} \%$, and the top (the 1st), middle (2nd) and bottom (3rd) layer contained $20 \mathrm{wt} \%, 30 \mathrm{wt} \%$ and $40 \mathrm{wt} \%$ of GNP/Ni, respectively, in the direction of the propagation of incident wave. The 1st layer $\{20 \mathrm{wt} \% \mathrm{GNP} / \mathrm{Ni}\}$ adopts less amount of conductive filler than the monolayered sample; this can lead to higher impedance $\left(Z_{1}\right)$. The reflection of incident waves results from the mismatch of impedance between the material's surface and the air. ${ }^{23}$ As the GNP/Ni concentration in the surface of the material decreases, the impedance gap between the material and the air becomes smaller. Therefore, this structure can maximize the fraction of incident wave that enters the material by minimizing the impedance gap between the 1st layer and the air. ${ }^{24}$ The 1 st layer presents an intense penetrating capability, and the following layers have stronger absorption and reflection capability. As the concentration of GNP/Ni in a layer increases from top to bottom, the conductivity of the layer increases, and the impedance decreases; this results in an increase in both the reflection and the absorption capability. The wave approaching the multilayered structure can enter deeper through the material and can be more fully attenuated by the GNP/Ni filler than that when a monolayered nanocomposite is used. ${ }^{23,24}$ In addition, an abrupt concentration difference of $10 \mathrm{wt} \%$ between contacting layers induces an additional internal reflection between layers. Since the thickness of each layer is larger than the skin depth, which is the distance up to which the intensity of a wave decreases to $1 / e$ of its original strength, ${ }^{9}$ waves reflected between layers dissipate into heat energy. ${ }^{25}$ This factor can be added to the $\mathrm{SE}_{\mathrm{A}}$ of the mutilayered structure. For these reasons, the multilayered structure can improve the shielding capability of a material without increasing the total amount of GNP/Ni.

The EMI SE of a material can be defined as the ratio of the incident power (energy) to the transmitted power (energy),

$$
\mathrm{SE}(\mathrm{dB})=10 \log \left(P_{\mathrm{i}} / P_{\mathrm{t}}\right)=20 \log \left(E_{\mathrm{i}} / E_{\mathrm{t}}\right)
$$

where $P_{\mathrm{i}}$ and $P_{\mathrm{t}}$ are the incident and transmitted electromagnetic power, respectively. ${ }^{26}$ Total $\mathrm{SE}\left(\mathrm{SE}_{\mathrm{T}}\right)$ is the summation of $\mathrm{SE}$ due to reflection $\left(\mathrm{SE}_{\mathrm{R}}\right)$, absorption $\left(\mathrm{SE}_{\mathrm{A}}\right)$ and multiplereflection $\left(\mathrm{SE}_{\mathrm{M}}\right)$, as presented in the following eqn (5).

$$
\mathrm{SE}_{\mathrm{T}}=\mathrm{SE}_{\mathrm{R}}+\mathrm{SE}_{\mathrm{A}}+\mathrm{SE}_{\mathrm{M}}
$$

Since the skin depth is larger than the thickness of each layer, the internal reflection between layers due to difference in impedances is considered as absorption, which has been discussed in detail in Section 3.2. Therefore, the effective absorbance $\left(A_{\text {eff }}\right)$ with respect to the power of the effective incident wave inside the material can be expressed as eqn (6).

$$
A_{\text {eff }}=(1-R-T) /(1-R)
$$

$\mathrm{SE}_{\mathrm{R}}$ and $\mathrm{SE}_{\mathrm{A}}$ are calculated from transmission, reflection and absorption coefficients using the eqn (7) and (8), respectively. ${ }^{27}$

$$
\begin{gathered}
\mathrm{SE}_{\mathrm{R}}=-10 \log (1-R) \\
\mathrm{SE}_{\mathrm{A}}=-10 \log \left(1-A_{\text {eff }}\right)=-10 \log [T /(1-R)]
\end{gathered}
$$

Fig. 2 shows the $\mathrm{SE}_{\mathrm{R}}, \mathrm{SE}_{\mathrm{A}}$ and $\mathrm{SE}_{\mathrm{T}}$ values in the $\mathrm{X}$-band of the monolayered and multilayered GNP/Ni/PMMA nanocomposites represented in Fig. 1. In Fig. 2(a) and (b), the mutilayered structure has lower $\mathrm{SE}_{\mathrm{R}}$ and higher $\mathrm{SE}_{\mathrm{A}}$ values than the monolayered structure over the whole frequency range; this means much less incident wave from air reflects off the 1 st layer in the mutilayered structure than that in the case of the monolayered structure; as a result, a bigger fraction of the incident energy penetrates the surface of the material and attenuated through the material. As the impedance reaches closer to that of air, the reflection of the incoming waves from the surface decreases; thus, $\mathrm{SE}_{\mathrm{R}}$ and additional interference of the reflected wave are reduced. ${ }^{24,28}$ Fig. S $3 \dagger$ depicts the impedances calculated for each layer in the multilayered nanocomposite at 8, 9, 10, 11 and 12 

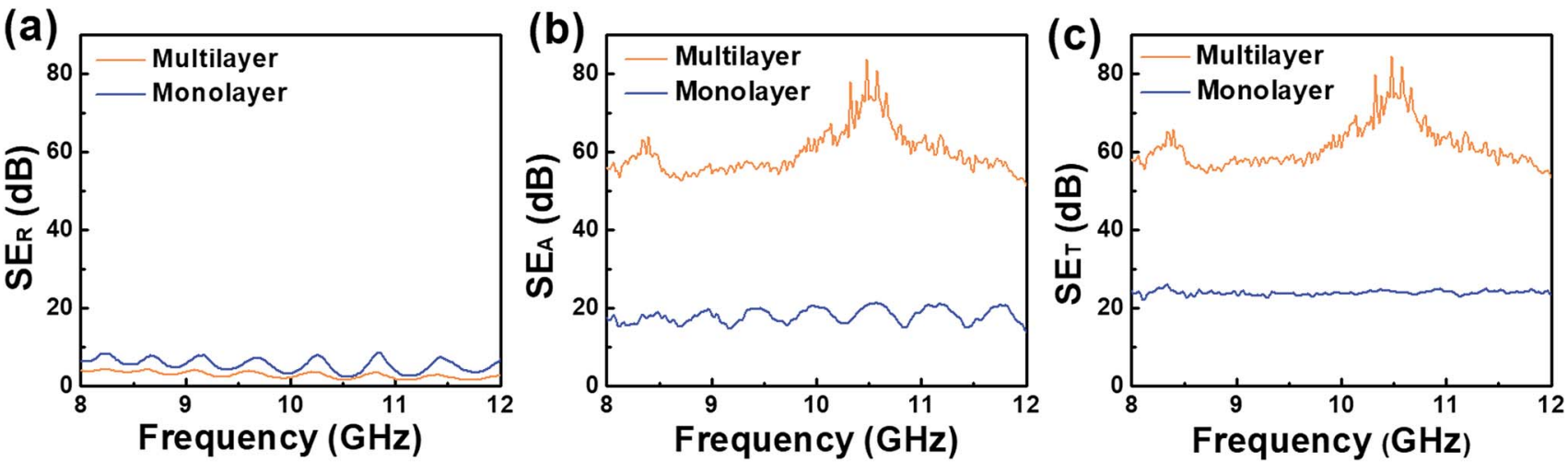

Fig. 2 (a) $\mathrm{SE}_{\mathrm{R}}$, (b) $\mathrm{SE}_{\mathrm{A}}$ and (c) $\mathrm{SE}_{\mathrm{T}}$ results of the monolayered and multilayered GNP/Ni/PMMA nanocomposites in Fig. 1(a) and (b).

GHz. The 1st layer has the impedances of $86 \Omega$ and $48 \Omega$ at 8 $\mathrm{GHz}$ and $12 \mathrm{GHz}$, which are higher than those in the 2nd layer with the same impedance as in the monolayered structure $(23 \Omega$ and $17 \Omega$ ), respectively. The impedance of the 1 st layer in the mutilayered structure is closer to that of air, i.e. $377 \Omega$, than to that of the monolayered structure. The impedance gap between the 1st layer and the air decreases with the decreasing amount of GNP/Ni. The reflection of waves incident to the material surface occurs due to impedance difference between them. A decrease in the impedance gap leads to a decrease in the overall reflection from the surface when a wave is incident and an increase in penetration through the material. ${ }^{29}$

In Fig. 2(c), the $\mathrm{SE}_{\mathrm{T}}$ value of the multilayered GNP/Ni/PMMA is $54-85 \mathrm{~dB}$, whereas that of the monolayered sample is $22-26$ $\mathrm{dB}$ for the same thickness. The major shielding mechanism in the multilayered structure is absorption by conductive dissipation. According to the SE results for the GNP/Ni/PMMA nanocomposite, the mutilayered structure shows superior shielding capability over the monolayered structure.

\subsection{Theoretical and experimental results of the multilayered GNP/Ni/PMMA nanocomposite}

To understand the mechanism of EMI shielding in the multilayered GNP/Ni/PMMA nanocomposite, as shown in Fig. 1(b), a theoretical calculation was carried out through plane-wave shielding theory developed for multiple sheets, ${ }^{30}$ and the results were compared with the experimental results.

For the calculation of the magnetic permeability of each layer in the GNP/Ni/PMMA nanocomposite, each single layer of $\{20 \mathrm{wt} \% \mathrm{GNP} / \mathrm{Ni}\},\{30 \mathrm{wt} \% \mathrm{GNP} / \mathrm{Ni}\}$ and $\{40 \mathrm{wt} \% \mathrm{GNP} / \mathrm{Ni}\}$ is respectively fabricated, and its $\mathrm{SE}_{\mathrm{A}}$ is measured (Fig. 3(a)). The relative magnetic permeability can be calculated using eqn (9), as shown in Fig. 3(b),

$$
\mathrm{SE}_{\mathrm{A}}=8.686 d_{n} \sqrt{\pi f \sigma_{n} \mu_{n}}
$$

where $d_{n}$ is the shielding thickness of the $n$th layer $(n=1,2$, and 3$)$, $f$ is the frequency, $\sigma_{n}$ is the electrical conductivity and $\mu_{n}$ is the magnetic permeability, which has a relationship of $\mu=\mu_{0} \mu_{\mathrm{r}}\left(\mu_{0}=\right.$ $\left.4 \pi \times 10^{-7} \mathrm{H} \mathrm{m}^{-1}\right) \cdot^{31}$ The thickness, the electrical conductivity and the skin depth at 8 and $12 \mathrm{GHz}$ of each layer are listed in Table S1. $\dagger$
For conductive materials, if $\sigma \gg 2 \pi f \varepsilon_{0}\left(\varepsilon_{0}=8.854 \times 10^{-12} \mathrm{~F} \mathrm{~m}^{-1}\right)$, the skin depth of the $n$th layer $\left(\delta_{n}\right)$ can be calculated by eqn (10). ${ }^{32}$

$$
\delta_{n}=\frac{1}{\sqrt{\pi f \sigma_{n} \mu_{n}}}
$$

Since the conductivities of all layers are higher than $2 \pi f \varepsilon_{0}$ at 8 and $12 \mathrm{GHz}(0.445$ and 0.668 , see Table S1 $\dagger)$, the skin depth was calculated using eqn (10).

When a wave is incident from the air to the surface of a conductive material, if $Z_{0}^{2} \gg Z_{1}$, where $Z_{0}\left(Z_{0}^{2}=\mu_{0} / \varepsilon_{0}\right)$ and $Z_{1}$ $\left(Z_{1}^{2}=2 \pi f \mu_{1} / \sigma_{1}\right)$ is the impedance of air and that of the 1 st layer, the $\mathrm{SE}_{\mathrm{R}}$ of the multilayered structure can be written as eqn (11). ${ }^{32}$

$$
\mathrm{SE}_{\mathrm{R}}=20 \log \left(\frac{Z_{0}}{4 Z_{1}}\right)=20 \log \left(\frac{\sqrt{\mu_{0} \sigma}}{4 \sqrt{2 \pi f \mu \varepsilon_{0}}}\right)
$$

The reflection between the $n-1$ th and $n$th layer inside the mutilayered structure is presented by the following eqn (12),

$$
\mathrm{SE}_{\mathrm{R}}=20 \log \left(\frac{1}{2}\left|1+\frac{Z_{n}}{Z_{n-1}}\right|\right)
$$

where $Z_{n-1}$ and $Z_{n}$ is the impedance of the $n-1$ th and $n$th layer, respectively. ${ }^{32}$ The reflected wave between layers can be absorbed when it propagates inside the material because the thickness of each layer is larger than the skin depth..$^{33}$ The reflection terms between the 1st and 2nd, 2nd and 3rd layer are added to the $\mathrm{SE}_{\mathrm{A}}$ of the multilayered structure. Therefore, the $\mathrm{SE}_{\mathrm{A}}$ of the multilayered structure can be expressed by the eqn (13).

$$
\begin{aligned}
\mathrm{SE}_{\mathrm{A}}= & 8.686\left(\frac{d_{1}}{\delta_{1}}+\frac{d_{2}}{\delta_{2}}+\cdots+\frac{d_{n}}{\delta_{n}}\right)+20 \log \left(\frac{1}{2}\left|1+\frac{Z_{2}}{Z_{1}}\right|\right)+\cdots \\
& +20 \log \left(\frac{1}{2}\left|1+\frac{Z_{n}}{Z_{n-1}}\right|\right)
\end{aligned}
$$

$\mathrm{SE}_{\mathrm{A}}$ consists of absorption terms of each layer and reflection terms between layers with different GNP/Ni concentrations. The value of $\mathrm{SE}_{\mathrm{A}}$ is a function of the thickness of the material as well 
(a)

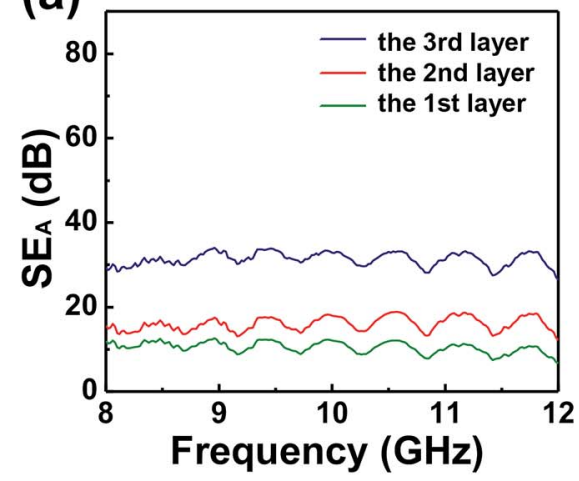

(b)

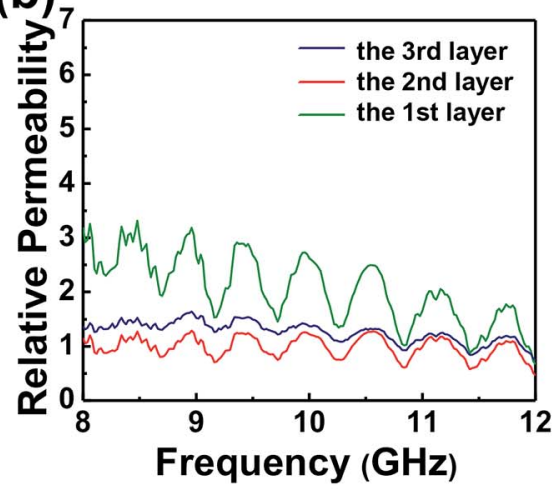

(c)

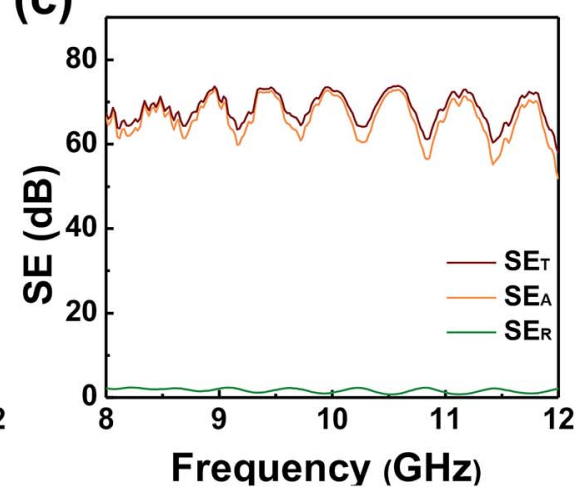

Fig. 3 (a) $\mathrm{SE}_{\mathrm{A}}$ and (b) relative permeability of each layer in the multilayered GNP/Ni/PMMA nanocomposite (\{20 wt\% GNP/Ni $\} /\{30$ wt $\%$ GNP/Ni $/$ $\left\{40\right.$ wt\% GNP/Ni\}). (c) Calculation results for $\mathrm{SE}_{\mathrm{R}}, \mathrm{SE}_{\mathrm{A}}$ and $\mathrm{SE}_{\mathrm{T}}$ of the multilayered GNP/Ni/PMMA nanocomposite.

as the electrical conductivity and the permeability. Since each layer has the same thickness, the conductivity and magnetic permeability are variables in $\mathrm{SE}_{\mathrm{A}}$.

The calculation of $\mathrm{SE}_{\mathrm{T}}, \mathrm{SE}_{\mathrm{R}}$ and $\mathrm{SE}_{\mathrm{A}}$ of the mutilayered $\mathrm{GNP} /$ Ni/PMMA nanocomposite ( $\{20$ wt $\%$ GNP/Ni $\} /\{30$ wt $\%$ GNP/Ni $\} /$ $\{40 \mathrm{wt} \% \mathrm{GNP} / \mathrm{Ni}\}$ ) was carried out using the eqn $(5),(11)$ and (13), respectively. Fig. 3(c) shows the calculated values of $\mathrm{SE}_{\mathrm{R}}$, $\mathrm{SE}_{\mathrm{A}}$ and $\mathrm{SE}_{\mathrm{T}}$ of the mutilayered structure. The investigation of the EMI shielding mechanism demonstrates that the most part of the incident wave is absorbed after it penetrates the material due to the high impedance of the 1st layer, inducing a decrease in $\mathrm{SE}_{\mathrm{R}}$. Once the incident wave propagates into layers, it is attenuated by conductive dissipation and extra internal reflection between layers. It contributes to $\mathrm{SE}_{\mathrm{A}}$, which constitutes the largest part of $\mathrm{SE}_{\mathrm{T}}$.

The experimental results shown in Fig. 2 and the calculation results were compared to investigate whether the shielding properties of the mutilayered structure match with a theoretical mechanism. Fig. 4 shows the theoretical and experimental results for $\mathrm{SE}_{\mathrm{R}}, \mathrm{SE}_{\mathrm{A}}$ and $\mathrm{SE}_{\mathrm{T}}$ of the multilayered GNP/Ni/PMMA nanocomposite shown in Fig. 1(b). According to the results, SE due to absorption is much higher than that due to reflection; this demonstrates that absorption is the major shielding mechanism in the multilayered GNP/Ni/PMMA nanocomposite. Therefore, the multilayered system shows $\mathrm{SE}_{\mathrm{T}}$ of 54-85 $\mathrm{dB}$, which is 1585 times that of the monolayered system $(22-26 \mathrm{~dB}$, see Fig. 2(c)). Once the incident wave is applied on a material, absorption inside the whole material can dominantly affect the EMI shielding properties as a result of the absorption of each layer and internal reflection between layers.

In addition, the two peaks shown in Fig. 4(b) and (c) are responsible for resonance absorption due to the effects of mutilayered structure and the thickness. ${ }^{9}$ The increase in absorption results from the cancellation of wave reflected from the surface of the material and at the rear surface. Therefore, $\mathrm{SE}_{\mathrm{T}}$ increases in the designated range of frequency.

Fig. 5 shows the EMI shielding properties of the recently reported graphene/nanoparticle/polymer and multilayered nanocomposite materials in the X-band region. Various EMI shielding structures have been reported using graphene/ nanoparticle/polymer system to increase internal reflection inside a material. Despite of various EMI shielding structures reported in the recent literature, multilayered system using GNP, Ni nanoparticle and PMMA can take advantages of easy fabrication process, which are favorable from an engineering point-of-view.
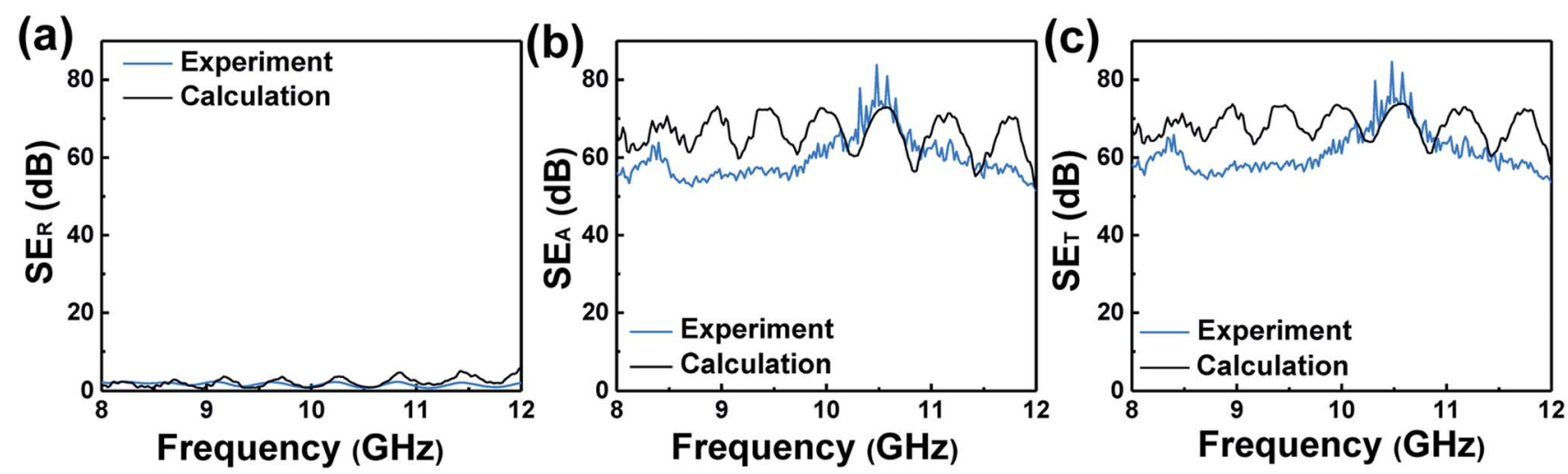

Fig. 4 Theoretical and experimental results for the multilayered GNP/Ni/PMMA nanocomposite (\{20 wt\% GNP/Ni\}/\{30 wt\% GNP/Ni\}/\{40 wt\% GNP/Ni\}); (a) $\mathrm{SE}_{\mathrm{R}}$, (b) $\mathrm{SE}_{\mathrm{A}}$ and (c) $\mathrm{SE}_{\mathrm{T}}$. 


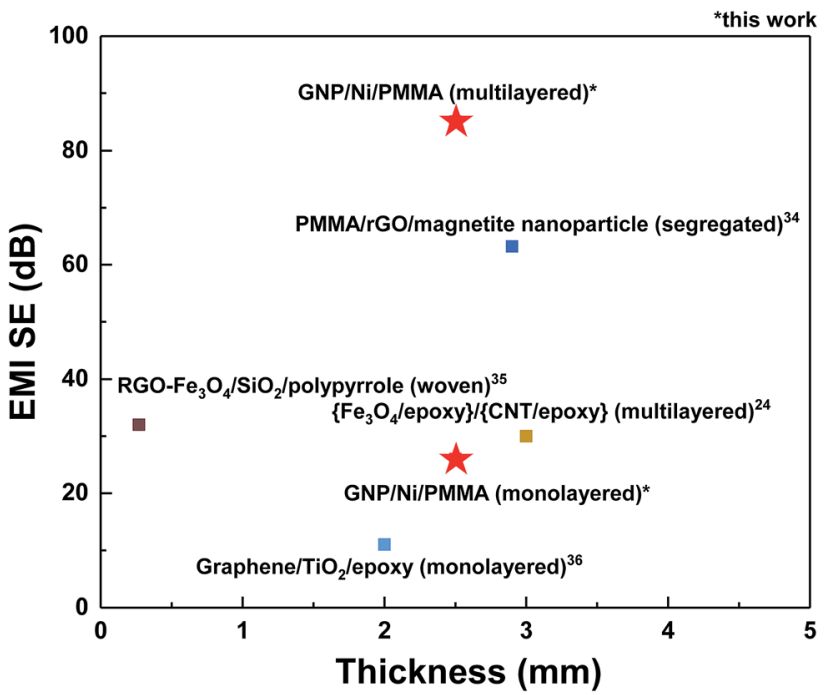

Fig. 5 EMI shielding properties of the recently reported graphene/ nanoparticle/polymer nanocomposite materials with various structures.

\section{Conclusions}

Herein, multilayered GNP/Ni/PMMA nanocomposites ( $\{20 \mathrm{wt} \%$ GNP/Ni $\} /\{30 \mathrm{wt} \% \mathrm{GNP} / \mathrm{Ni}\} /\{40 \mathrm{wt} \% \mathrm{GNP} / \mathrm{Ni}\})$ and monolayered GNP/Ni/PMMA nanocomposites $\{30 \mathrm{wt} \% \mathrm{GNP} / \mathrm{Ni}\}$ were fabricated with the objective of maximizing the EMI shielding properties of the GNP/Ni nanocomposite at a given amount in a matrix. Multilayered nanocomposites were designed by increasing the GNP/Ni weight fraction by $10 \mathrm{wt} \%$ between the contacting layers; this led to an abrupt increase in the conductivity along the wave propagation direction. Their SE were measured and compared in terms of the contribution of multilayered structures to EMI shielding. Furthermore, the theoretical and experimental results of the multilayered structure show similar trends; this makes it possible to investigate the EMI shielding mechanism. The main factors responsible for the enhancement of the shielding capability of the multilayered nanocomposites were the increase in the absorption and reflection capabilities of the 2nd and 3rd layers and additional reflection. Moreover, reflection from the surface of the material could be minimized by increasing the impedance of the 1st layer. Therefore, our studies on multilayered nanocomposites using $\mathrm{GNP} / \mathrm{Ni}$ in the polymer matrix can be exploited for designing improved EMI shielding material where their thickness and amount of conductive fillers are limited. This system can maximize the EMI shielding properties by inducing additional internal reflections that result from abrupt impedance changes. This strategy can be applied to various scales and kinds of material.

\section{Conflicts of interest}

There are no conflicts to declare.

\section{Acknowledgements}

This work was supported by the Nano-Material Technology Development Program through the National Research
Foundation of Korea (NRF) funded by the Ministry of Science, ICT and Future Planning [grant number 2016M3A7B4905609].

\section{References}

1 J. Liang, Y. Wang, Y. Huang, Y. Ma, Z. Liu, J. Cai, C. Zhang, H. Gao and Y. Chen, Carbon, 2009, 47, 922-925.

2 P. C. P. Watts, W.-K. Hsu, A. Barnes and B. Chambers, Adv. Mater., 2003, 15, 600-603.

3 S. Ryu, C. B. Mo, H. Lee and S. H. Hong, J. Nanosci. Nanotechnol., 2013, 13, 7669-7674.

4 Y. Li, X. Pei, B. Shen, W. Zhai, L. Zhang and W. Zheng, RSC Adv., 2015, 5, 24342-24351.

5 W.-L. Song, L.-Z. Fan, M.-S. Cao, M.-M. Lu, C.-Y. Wang, J. Wang, T.-T. Chen, Y. Li, Z.-L. Hou, J. Liu and Y.-P. Sun, J. Mater. Chem. C, 2014, 2, 5057-5064.

6 V. Eswaraiah, V. Sankaranarayanan and S. Ramaprabhu, Macromol. Mater. Eng., 2011, 296, 894-898.

7 A. P. Singh, M. Mishra, D. P. Hashim, T. N. Narayanan, M. G. Hahm, P. Kumar, J. Dwivedi, G. Kedawat, A. Gupta, B. P. Singh, A. Chandra, R. Vajtai, S. K. Dhawan, P. M. Ajayan and B. K. Gupta, Carbon, 2015, 85, 79-88.

8 M. Verma, P. Verma, S. K. Dhawan and V. Choudhary, RSC $A d v .$, 2015, 5, 97349-97358.

9 M. Verma, A. P. Singh, P. Sambyal, B. P. Singh, S. K. Dhawan and V. Choudhary, Phys. Chem. Chem. Phys., 2015, 17, 16101618.

10 S. Kim, J. Oh, M. Kim, W. Jang, M. Wang, Y. Kim, H. W. Seo, Y. C. Kim, J. Lee, Y. Lee and J. Nam, ACS Appl. Mater. Interfaces, 2014, 6, 17647-17653.

11 S. K. Hong, K. Y. Kim, T. Y. Kim, J. H. Kim, S. W. Park, J. H. Kim and B. J. Cho, Nanotechnology, 2012, 23, 455704.

12 W. Li, D. Li, Q. Fu and C. Pan, RSC Adv., 2015, 5, 8042880433.

13 Y. Tong, S. Bohm and M. Song, Austin J. Nanomed. Nanotechnol., 2014, 1, 1003.

14 D. A. C. Brownson and C. E. Banks, Phys. Chem. Chem. Phys., 2012, 14, 8264-8281.

15 H. J. Im, G. H. Jun, D. J. Lee, H. J. Ryu and S. H. Hong, J. Mater. Chem. C, 2017, 5, 6471-6479.

16 S. Stankovich, D. A. Dikin, R. D. Piner, K. A. Kohlhaas, A. Kleinhammes, Y. Jia, Y. Wu, S. T. Nguyen and R. S. Ruoff, Carbon, 2007, 45, 1558-1565.

17 Z. Wang, J. Luo and G. Zhao, AIP Adv., 2014, 4, 017139.

18 J. Hwang, T. Yoon, S. H. Jin, J. Lee, T.-S. Kim, S. H. Hong and S. Jeon, Adv. Mater., 2013, 25, 6724-6729.

19 J. R. Potts, D. R. Dreyer, C. W. Bielawski and R. S. Ruoff, Polymer, 2011, 52, 5-25.

20 H. B. Zhang, Q. Yan, W. G. Zheng, Z. He and Z. Z. Yu, ACS Appl. Mater. Interfaces, 2011, 3, 918-924.

21 S.-T. Hsiao, C.-C. M. Ma, H.-W. Tien, W.-H. Liao, Y.-S. Wang, S.-M. Li, C.-Y. Yang, S.-C. Lin and R.-B. Yang, ACS Appl. Mater. Interfaces, 2015, 7, 2817-2826.

22 S. Stankovich, D. A. Dikin, G. H. B. Dommett, K. M. Kohlhaas, E. J. Zimney, E. A. Stach, R. D. Piner, S. T. Nguyen and R. S. Ruoff, Nature, 2006, 442, 282-286. 
23 M. Chen, Y. Zhu, Y. Pan, H. Kou, H. Xu and J. Guo, Mater. Des., 2011, 32, 3013-3016.

24 Y. Liu, D. Song, C. Wu and J. Leng, Composites, Part B, 2014, 63, 34-40.

25 L. Q. Zhang, B. Yang, J. Teng, J. Lei, D. X. Yan, G. J. Zhong and Z. M. Li, J. Mater. Chem. C, 2017, 5, 3130-3138.

26 N. F. Colaneri and L. W. Shacklette, IEEE Trans. Instrum. Meas., 1992, 41, 291-297.

27 A. Joshi, A. Bajaj, R. Singh, A. Anand, P. S. Alegaonkar and S. Datar, Composites, Part B, 2015, 69, 472-477.

28 Y. Chen, Y. Li, M. Yip and N. Tai, Compos. Sci. Technol., 2013, 80, 80-86.

29 Y. Xu, Y. Yang, D. X. Yan, H. Duan, G. Zhao and Y. Liu, ACS Appl. Mater. Interfaces, 2018, 10, 19143-19152.
30 B. R. Schulz, V. C. Plzntz and D. R. Brush, IEEE Trans. Electromagn. Compat., 1988, 30, 187-201.

31 L. Vovchenko, Y. Perets, I. Ovsienko, L. Matzui, V. Oliynyk and V. Launetz, Surf. Coat. Technol., 2012, 211, 196-199.

32 W. L. Song, M. S. Cao, M. M. Lu, S. Bi, C. Y. Wang, J. Liu, J. Yuan and L. Z. Fan, Carbon, 2014, 66, 67-76.

33 M. H. Al-Saleh and U. Sundararaj, Carbon, 2009, 47, 17381746.

34 F. Sharif, M. Arjmand, A. A. Moud, U. Sundararaj and E. P. L. Roberts, ACS Appl. Mater. Interfaces, 2017, 9, 14171-14179.

35 Y. Yuan, W. Yin, M. Yang, F. Xu, X. Zhao, J. Li, Q. Peng, X. He, S. Du and Y. Li, Carbon, 2018, 130, 59-68.

36 A. Kumar, R. Anant, K. Kumar, S. S. Chauhan, S. Kumar and R. Kumar, RSC Adv., 2016, 6, 113405. 